\title{
ESTUDO COMPARATIVO DE RESISTÊNCIA À CORROSÃO ENTRE LIGAS METÁLICAS FERROSAS E NÃO FERROSAS*
}

Francisco Alberto Marreiros da Rocha Filho ${ }^{1}$ Marcelo José Gomes da Silva²

\section{Resumo}

A corrosão é um fenômeno que está intimamente ligado à integridade dos metais e de suas ligas. Esta ocorre de diversas formas, uma das principais é a corrosão localizada na forma de pites, objeto de análise desse estudo, que visa estabelecer um comparativo entre as curvas de polarização cíclica de algumas ligas ferrosas e não ferrosas, ensaiadas em solução de $\mathrm{NaCl}$ 0,6 M, mostrando a agressividade que a solução exerce sob cada uma das ligas. Os materiais analisados nesse estudo foram os aços inoxidáveis AISI 304, AISI 444, super duplex ASTM A890/A890 M Grau 6A, o aço carbono AISI 1030, o alumínio comercialmente puro, o cobre eletrolítico e a liga zircaloy4. Inicialmente foram medidos os potenciais de corrosão (Ec) de cada liga através do monitoramento do potencial de circuito aberto. Foram realizados os ensaios de polarização potenciodinâmica cíclica em cada liga, comparando o aspecto superficial antes e depois do ensaio através de micrografias óticas, possibilitando que fossem observadas as diferenças entre cada material quanto à resistência à corrosão por pites. Observou-se que algumas ligas não apresentam passivação como o caso do alumínio comercialmente puro, e outras apresentaram regiões passivas e histereses bem definidas, ficando evidente que, dentre as ligas analisadas, o aço inoxidável super duplex ASTM A890/A890 M Grau 6A apresentou os melhores resultados frente aos efeitos agressivos dos íons $\mathrm{Cl}^{-}$presentes na solução, sendo o menos suscetível à corrosão por pites.

Palavras-chave: Corrosão por pites; Polarização cíclica; $\mathrm{NaCl}$ 0,6M; Ligas não ferrosas.

\section{COMPARATIVE STUDY OF CORROSION RESISTANCE BETWEEN FERROUS AND NONFERROUS METALLIC ALLOYS}

\section{Abstract}

Corrosion is a phenomenon that is closely linked to the integrity of the metal and its alloys. This occurs in many ways, one of the main is localized corrosion in the form of pits, object of analysis in this study, that aims to establish a comparison between the cyclic polarization curves of some ferrous and non-ferrous alloys, tested in $0,6 \mathrm{M} \mathrm{NaCl}$ solution, showing aggressivity the solution exerts on each of the alloys. The materials analyzed in this study were the stainless steel AISI 304, AISI 444, super duplex ASTM A890 / A890 M Grade 6A, carbon steel AISI 1030, commercially pure aluminum, electrolytic copper and zircaloy-4 alloy. Initially the corrosion potentials were measured (Ec) from each alloy through the open circuit potential monitoring. The cyclic potentiodynamic polarization tests on each alloy were conducted, comparing the surface appearance before and after the test by optical micrographs, enabling that differences were observed between each material for resistance to pitting corrosion. It was observed that some alloys do not exhibit passivation such as the case of commercially pure aluminum, and others showed passive regions and well defined hysteresis, being evident that, among the examined alloys, super duplex stainless steel ASTM A890 / A890 M Grade 6A presented best results against the harsh effects of $\mathrm{Cl}^{-}$ions present in the solution, being less susceptible to pitting corrosion.

Keywords: Pitting corrosion; Cyclic Polarization; 0.6M NaCl; Nonferrous alloys.

1 Engenheiro Metalurgista, Bacharel, Mestrando em Engenharia e Ciência de Materiais, Campus do Pici - CT - Depto. de Engenharia Metalúrgica e de Materiais - bloco 729 Pici, Universidade Federal do Ceará, Fortaleza, Ceará, Brasil.

2 Ph.D, Doutor em Engenharia Nuclear, Professor Adjunto, Campus do Pici - CT - Depto. de Engenharia Metalúrgica e de Materiais - bloco 729 Pici, Universidade Federal do Ceará, Fortaleza, Ceará, Brasil. 


\section{INTRODUÇÃO}

\subsection{Motivação}

A corrosão é um problema que afeta as mais variadas atividades. Com base nos efeitos danosos que a corrosão pode proporcionar se faz necessário o conhecimento das características e propriedades desta em diversos materiais metálicos, a fim de adequar o uso de um material em determinada aplicação, com o objetivo de atenuar os efeitos degradantes, aumentando assim a vida útil dos equipamentos e reduzindo assim os custos com reparos e substituições de peças, perdas de produção e exploração adicional de recursos minerais. [1,2]

\subsection{Objetivos}

Este trabalho foi realizado com o intuito de investigar e comparar a resistência à corrosão localizada na forma de pites através do monitoramento do potencial de circuito aberto e da realização de ensaios de polarização cíclica em solução de $\mathrm{NaCl}$ 0,6M, dos aços inoxidáveis austenítico (AISI 304), ferrítico (AISI 444), ASTM A890/A890 M Grau 6A designado como aço inoxidável super duplex (AISD), do aço carbono (AISI 1030), do alumínio comercialmente puro (ACP), do cobre eletrolítico (CEL) e da liga zircaloy-4 (ZR-4), analisando os parâmetros obtidos nas curvas, comparando o aspecto superficial das amostras antes e depois da realização do ensaio de polarização cíclica, e por fim estabelecendo um comparativo geral entre as curvas obtidas para as ligas em estudo.

\subsection{Polarização Cíclica}

A técnica eletroquímica que ganhou a aceitação mais difundida como uma ferramenta geral para avaliar a possibilidade de uma liga sofrer corrosão localizada provavelmente é a técnica de polarização potenciodinâmica cíclica. Nesta técnica o potencial é aplicado ao eletrodo de trabalho (ET) em estudo e elevado a uma taxa contínua em relação a um eletrodo de referência (ER) utilizando um potenciostato. Geralmente a varredura é iniciada a partir do potencial de corrosão $\left(E_{c}\right)$. O potencial é aumentado primeiro na direção anódica ou direção nobre, e em alguma corrente ou potencial escolhido, a direção de varredura do potencial é invertida para a direção catódica ou ativa. Então a varredura é concluída em determinado potencial escolhido, seja ele o $E_{c}$ ou algum outro potencial ativo.

O potencial de quebra da passivação $\left(E_{b d}\right)$ é o potencial acima do qual os pites são iniciados, enquanto o potencial de repassivação $\left(E_{r p}\right)$ é o potencial abaixo do qual os pites se repassivam. [3,4]

\section{MATERIAIS E MÉTODOS}

\subsection{Análise Química}

Foram realizadas análises químicas nas amostras fornecidas para determinação da composição química das ligas metálicas e consequentemente sua identificação. As amostras inicialmente fornecidas eram genericamente conhecidas como: aço inoxidável austenítico, aço inoxidável ferrítico, aço inoxidável super duplex, aço carbono, liga de alumínio, liga de cobre e liga de zircônio. 
Para a identificação dos teores dos elementos de liga presentes em todas as amostras, exceto o aço carbono, as análises químicas foram realizadas utilizando-se a técnica Espectroscopia de Raios-X por Dispersão de Energia (EDX). Para a identificação da composição química do aço carbono, identificação do teor de carbono e de alguns elementos não identificados pela técnica EDX nos aços inoxidáveis, foi utilizada a técnica de Espectrometria de Emissão Ótica (OES), técnica capaz de detectar diversos elementos inclusive elementos de baixo número atômico como o carbono.

A análise química pela técnica EDX foi realizada utilizando o Microscópio Eletrônico de Varredura da marca Tescan, modelo VEGA3-XM com tensão de aceleração de $20 \mathrm{KV}$, no modo EDX, equipamento esse presente no Instituto de Pesquisa, Desenvolvimento e Inovação (IPDI - CE). A análise química utilizando a técnica OES foi realizada utilizando o Espectrômetro de Emissão Óptica da marca Shimadzu, modelo PDA-7000, equipamento esse presente no Laboratório de Caracterização de Materiais (LACAM-UFC).

\subsection{Preparação das amostras para Ensaios de Polarização}

Foram montados os eletrodos com a fixação de fios de cobre nas amostras, responsáveis pelo contato elétrico entre o potenciostato e a amostra. Então foi preparada a resina para realização do embutimento a frio, a amostra com o fio encaixado foi posicionada sobre uma superfície plana e lisa juntamente com um segmento de tubo de PVC, então a resina líquida foi despejada no interior do tubo. Após aproximadamente 24 horas a resina está completamente curada. Após a montagem dos eletrodos, as superfícies das amostras foram preparadas através de lixamento com lixas de carbeto de silício $(\mathrm{SiC})$ de granulometrias cada vez menores. Essa operação tem como objetivo eliminar camadas de óxidos, riscos e marcas mais profundas da superfície, preparando as amostras para a realização bem sucedida dos ensaios eletroquímicos. As lixas utilizadas foram as de granulometria 100, 220, 320,400 e 600.

\subsection{Ensaios Eletroquímicos}

Para a realização dos ensaios de polarização potenciodinâmica cíclica, foi montado um arranjo composto com béquer contendo o eletrólito, eletrodo de referência (ER), contra-eletrodo (CE), e eletrodo de trabalho (ET). Os eletrodos são conectados ao potenciostato, responsável por fornecer o potencial para a aquisição das curvas de polarização. O eletrólito utilizado foi uma solução de $\mathrm{NaCl}$ 0,6 M (35000 ppm) com $\mathrm{pH} \approx 6,80$ (neutro), solução essa com íons $\mathrm{Cl}^{-}$presente em ambientes marinhos. $\mathrm{O}$ eletrodo de referência utilizado foi o de $\mathrm{Ag} / \mathrm{AgCl}$, o contra-eletrodo de platina. Todos os ensaios foram realizados em temperatura ambiente $\left(\approx 25^{\circ} \mathrm{C}\right)$.

Foram realizadas medidas do potencial de corrosão $\left(E_{c}\right)$ através do monitoramento do potencial de circuito aberto. O tempo de monitoramento de potencial de circuito aberto utilizado foi de 7200 s (2h). Os ensaios de polarização potenciodinâmica cíclica foram realizados em triplicata para cada uma das ligas em estudo. $O$ procedimento para cada ensaio consistiu inicialmente na realização do monitoramento do potencial de circuito aberto por $1800 \mathrm{~s}$ (30 minutos) para cada amostra, em seguida o ensaio de polarização cíclica foi iniciado através da aplicação de potencial externo fornecido pelo potenciostato, com a varredura sendo iniciada a partir do potencial de corrosão, prosseguindo na direção anódica até que fosse 
atingido o potencial correspondente a corrente de $1 \mathrm{~mA}$, a partir desse ponto a varredura caminhou na direção reversa (direção catódica). A taxa de varredura foi de $1 \mathrm{mV} / \mathrm{s}$. O arranjo para a aquisição das curvas de polarização cíclica é mostrado na Figura 1.

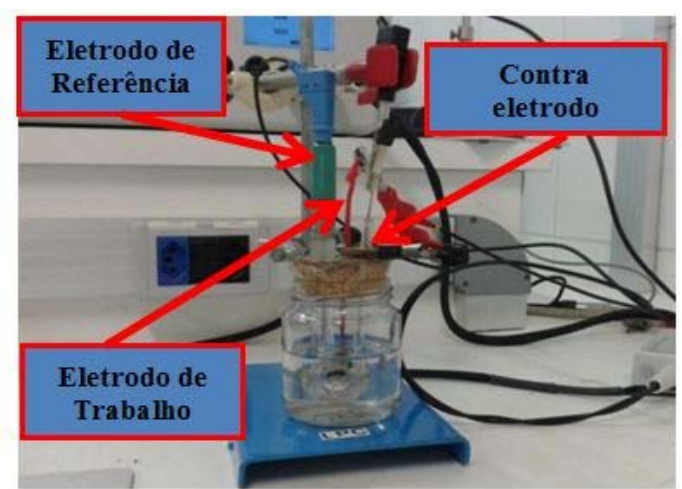

Figura 1 - Arranjo experimental utilizado para realização dos ensaios de polarização cíclica. Fonte: Própria do autor.

Para a realização dos ensaios eletroquímicos, foi utilizado o potenciostato da marca Metrohm, modelo PGSTAT302N, acoplado ao computador dotado do software Nova v.1.10.4 para registro dos dados. Para efeito de comparação foram realizadas as aquisições das micrografias das amostras antes e depois do ensaio de polarização cíclica em um microscópio ótico da marca LEICA, modelo DMI3000 M.

Para cada material, os ensaios de monitoramento do potencial de circuito aberto e de polarização potenciodinâmica cíclica foram realizados em triplicata de modo a se obter resultados consistentes e com a menor variabilidade.

\section{RESULTADOS E DISCUSSÃO}

\subsection{Resultados da Análise Química}

Realizada a análise química nas ligas, foram obtidos os dados de composição, e a partir da análise dos teores de cada elemento presente, foi possível a classificação das ligas de acordo com os seus respectivos sistemas de nomenclatura. A Tabela 1 mostra a composição química de cada liga em estudo e a sua respectiva classificação de acordo com o sistema de nomenclatura.

Tabela 1 - Resumo dos dados adquiridos nas análises químicas das amostras.

Fonte: Própria do Autor

\begin{tabular}{|c|c|c|c|c|c|c|c|c|c|c|c|c|}
\hline Liga & $\% \mathrm{C}$ & $\% M n$ & $\% P$ & $\% \mathrm{~S}$ & $\% \mathrm{Si}$ & $\% \mathrm{Cr}$ & $\% \mathrm{Ni}$ & \%Mo & $\% \mathrm{Zr}$ & $\% \mathrm{Cu}$ & $\% \mathrm{Al}$ & $\%$ Sn \\
\hline Aço AISI 304 & 0,08 & 2,0 & 0,05 & 0,03 & 0,75 & 20,2 & 10,3 & - & - & - & - & - \\
\hline Aço AISI 444 & 0,03 & 1,0 & 0,04 & 0,03 & 1,0 & 18,2 & 0,96 & 1,9 & - & - & - & - \\
\hline $\begin{array}{l}\text { Aço ASTM } \\
\text { A890/A890 } \\
\text { M Grau 6A }\end{array}$ & 0,025 & 0,62 & 0,022 & 0,006 & 0,81 & 25,2 & 7,44 & 3,6 & 0,06 & 0,71 & 0,01 & - \\
\hline $\begin{array}{c}\text { Aço AISI } \\
1030\end{array}$ & 0,3 & 0,86 & 0,061 & 0,023 & 0,23 & 0,83 & 0,11 & - & - & - & - & - \\
\hline $\begin{array}{c}\text { Alumínio } \\
\text { C.P. }\end{array}$ & - & - & - & - & - & - & - & - & - & - & $\approx 100$ & - \\
\hline $\begin{array}{c}\text { Cobre } \\
\text { Eletrolítico }\end{array}$ & - & - & - & - & - & - & - & - & - & $\approx 100$ & - & - \\
\hline Zircaloy-4 & - & - & - & - & - & 0,11 & - & - & $\approx 98,5$ & - & - & 1,4 \\
\hline
\end{tabular}




\subsection{Monitoramento do Potencial de Circuito Aberto}

O monitoramento teve como objetivo a medição dos valores do potencial de corrosão para cada liga. A Figura 2 reúne as curvas com os potenciais de corrosão $\left(E_{c}\right)$ dos materiais em estudo. Nos gráficos dos ensaios eletroquímicos foram utilizadas abreviaturas para designar as ligas da seguinte forma: ACP (Alumínio Comercialmente Puro); CEL (Cobre Eletrolítico); ZR-4 (Zircaloy-4); AISI 304 (Aço Inoxidável 304); AISI 444 (Aço Inoxidável 444); AISD (Aço Inoxidável Super Duplex ASTM A890 Gr. 6A); AISI 1030 (Aço carbono 1030).

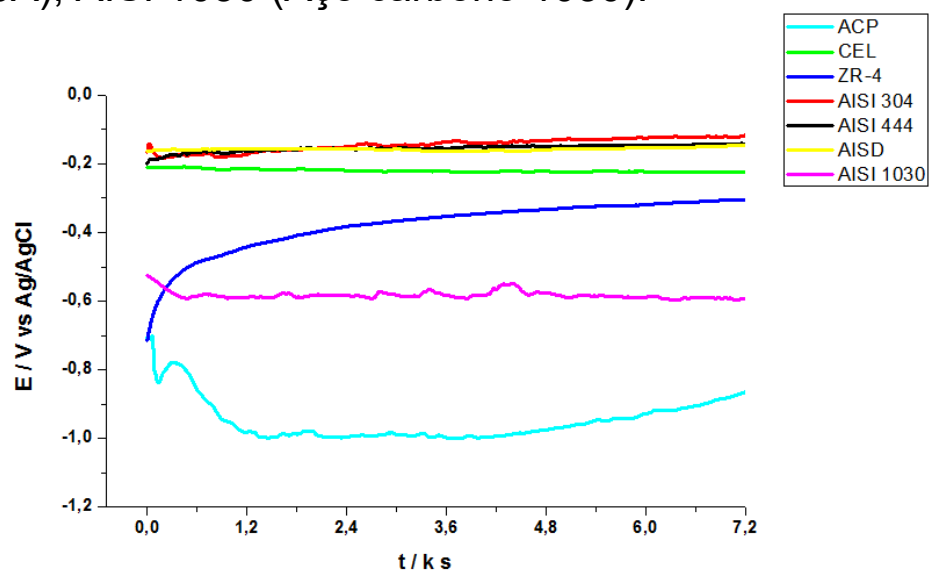

Figura 2 - Curvas de Monitoramento do potencial de circuito aberto para todas as ligas em estudo. Fonte: Própria do autor.

Com os valores obtidos, observou-se que os materiais com potencial de corrosão $\left(E_{c}\right)$ mais nobres são os aços inoxidáveis austenítico (AISI 304), ferrítico (AISI 444) e super duplex (AISD), estes apresentaram valores muito próximos entre si, devido a agressividade dos íons cloretos presentes na solução de $\mathrm{NaCl}$ 0,6 M. O zircaloy-4 (ZR-4), possui boa resistência à corrosão inerente às ligas de zircônio e também pelo fato da mesma possuir $\mathrm{Cr}$ e $\mathrm{Sn}$ em sua composição. Observou-se o potencial do alumínio comercialmente puro (ACP) como sendo o potencial menos nobre (mais negativo). Isso se deve ao fato do elemento alumínio possuir um dos potenciais mais ativos (mais negativos) na série galvânica dos metais, e isso se reflete no comportamento do ACP devido ao fato deste não possuir elementos de liga que possam proporcionar $E_{c}$ mais nobres.

\subsection{Ensaios de Polarização Cíclica}

Os ensaios de polarização cíclica têm como objetivo avaliar a suscetibilidade à corrosão por pites em materiais metálicos passiváveis através do surgimento de curvas de histerese durante a polarização. [5]

A susceptibilidade à corrosão por pites é baseada nos valores dos potenciais de quebra da passivação $\left(E_{b d}\right)$ e de repassivação $\left(E_{r p}\right)$. Valores de $E_{b d}$ próximos ao $E_{r p}$ indicam baixa susceptibilidade à corrosão por pites, enquanto valores baixos de $E_{r p}$ comparados com $E_{b d}$ indicam susceptibilidade à ocorrência de pites. [6]

Com o objetivo de estabelecer um comparativo entre todas as ligas em estudo, as curvas de polarização (valor médio das triplicatas) foram reunidas. A Figura 3 apresenta as curvas de polarização cíclica dos materiais onde não houve cruzamento entre as partes direta e reversa da curva. Observou-se que o alumínio comercialmente puro (ACP) apresentou potencial de corrosão $E_{c}$ inferior ao aço carbono (AISI 1030) e ao cobre eletrolítico (CEL), devido ao fato de que o alumínio apresenta um dos potenciais mais ativos na série galvânica dos metais, mas isso 
não significa que o ACP apresente baixa resistência à corrosão, pois a série galvânica diz respeito à espontaneidade das reações e não leva em consideração a cinética das reações. O CEL apresentou histerese positiva, indicando que a polarização do mesmo caminhou para potenciais mais nobres, tornando a superfície mais passiva e diminuindo assim a tendência deste sofrer corrosão por pites.

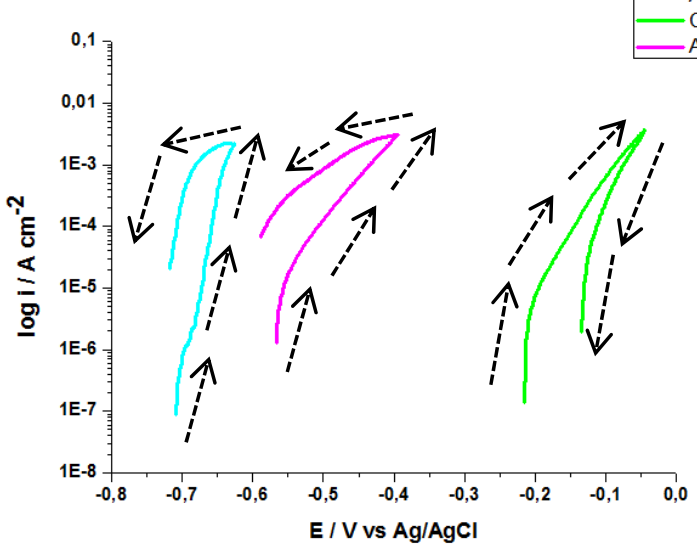

Figura 3 - Curvas de polarização cíclicas para as ligas onde não houve cruzamento das partes direta e reversa. Fonte: Própria do autor.

Houve o cruzamento entre as partes direta e reversa das curvas para quatro ligas que foram os aços inoxidáveis austenítico (AISI 304), ferrítico (AISI 444), super duplex (AISD), e para o zircaloy-4 (ZR-4). A Figura 4 apresenta as curvas de polarização cíclica desses materiais. Em termos do potencial de quebra da passivação $\left(E_{b d}\right)$, o maior valor obtido (mais nobre) foi o do aço inoxidável super duplex (AISD), sendo que quanto maior o $E_{b d}$, mais resistente é a liga a iniciação de sítios de corrosão localizada (pites). Os aços inoxidáveis austenítico (AISI 304) e ferrítico (AISI 444) apresentaram valores de $E_{b d}$ muito próximos entre si.

Quanto ao potencial de repassivação $\left(E_{r p}\right)$, a liga que apresentou o maior valor foi novamente o AISD, indicando que esta foi a liga mais facilmente repassivada. No que diz respeito à área de histerese, a liga que apresentou menor área foi o AISD, indicando menor probabilidade de propagação de sítios de corrosão localizada (pites) já iniciados. Devido as características agressivas da solução de $\mathrm{NaCl} 0,6 \mathrm{M}$, os aços AISI 304 e AISI 444 apresentaram comportamentos similares em diversos aspectos.

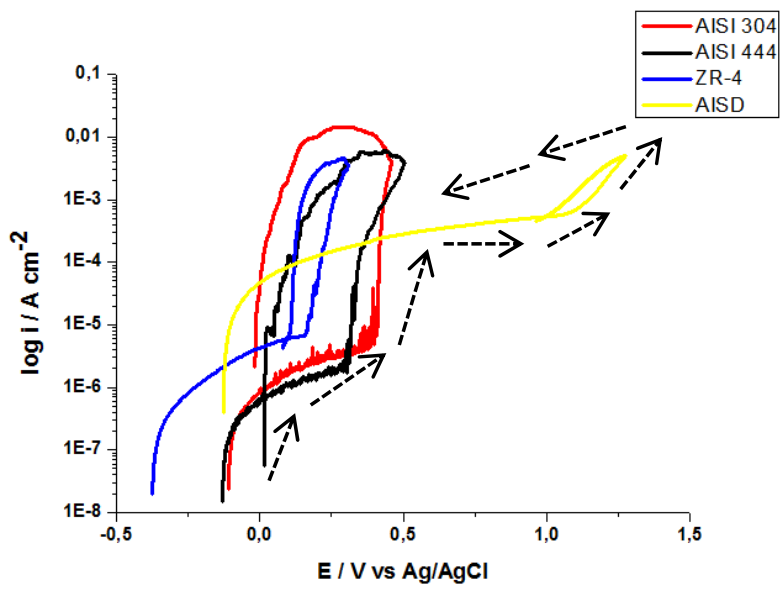

Figura 4 - Curvas de polarização cíclicas para as ligas onde houve cruzamento das partes direta e reversa. Fonte: Própria do autor. 
A Figura 5 mostra as curvas de todas as ligas em estudo, observou-se que o alumínio comercialmente puro (ACP), o aço carbono (AISI 1030) e o cobre eletrolítico (CEL) não apresentaram região passiva no ramo anódico da curva.

Quanto às ligas que apresentaram região passiva e área de histerese bem definidas, os aços inoxidáveis apresentaram valores de $\mathrm{E}_{\mathrm{c}}$ mais nobres, mas para todas essas ligas a parte reversa da curva direcionou-se a polarização de potenciais mais ativos (histerese negativa), indicando que essas apresentaram susceptibilidade à corrosão por pites, sendo que o aço inoxidável super duplex (AISD) apresentou o melhor resultado devido aos seus potenciais mais nobres e ao tamanho bem reduzido da área de histerese.

Os aços inoxidáveis super duplex possuem elevada resistência à corrosão em ambientes contendo os íons $\mathrm{Cl}^{-}$, os quais são muito comuns na água do mar. A maior resistência à corrosão por pites é ocasionadas pelas adições de Mo e $\mathrm{N}$ e pelo elevado teor de cromo. O ideal é que essa liga possua um teor de ferrita de cerca de $50 \% .[7,8]$

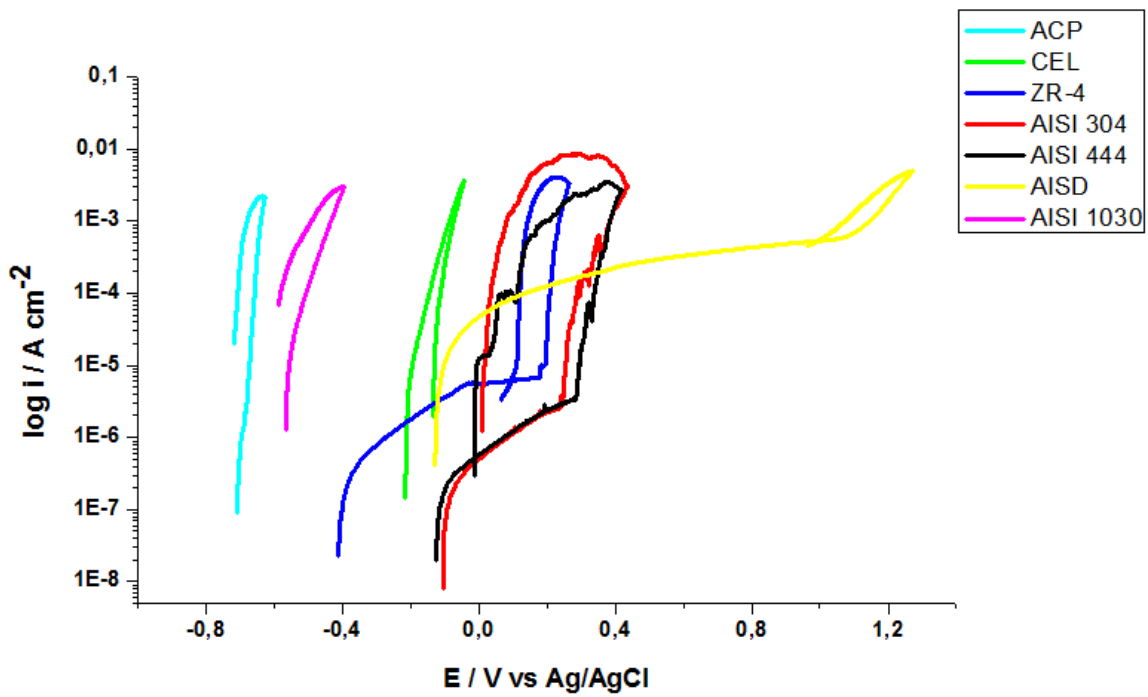

Figura 5 - Curvas de polarização cíclicas para todas as ligas em estudo. Fonte: Própria do autor.

A Figura 6 mostra um comparativo das micrografias óticas das ligas antes e após a realização dos ensaios de polarização cíclica. Em conformidade com as curvas obtidas e analisando as imagens, foi observado que o aço carbono (AISI 1030) e o cobre eletrolítico (CEL) apresentaram corrosão de forma generalizada e o alumínio comercialmente puro (ACP) apresentou corrosão na forma de pites. Os aços inoxidáveis austenítico (AISI 304) e ferrítico (AISI 444) apresentaram corrosão na forma de pites com o aspecto de superfície similar após o ensaio, sendo condizentes com os parâmetros similares obtidos nas curvas de polarização para ambas as ligas. A liga Zircaloy-4 apresentou corrosão na forma de pites, com o tamanho dos pites aparentemente menores se comparados aos apresentados pelos aços inoxidáveis, havendo uma relação direta com o tamanho reduzido da área de histerese apresentada por essa liga. O aço inoxidável super duplex ASTM A 890/ A 890M Grau 6A (AISD) apresentou a menor quantidade de pites entre todas as ligas que sofreram corrosão por pites, sendo coerente com as curvas obtidas e confirmando que essa liga possui ótima resistência à corrosão por pites. 

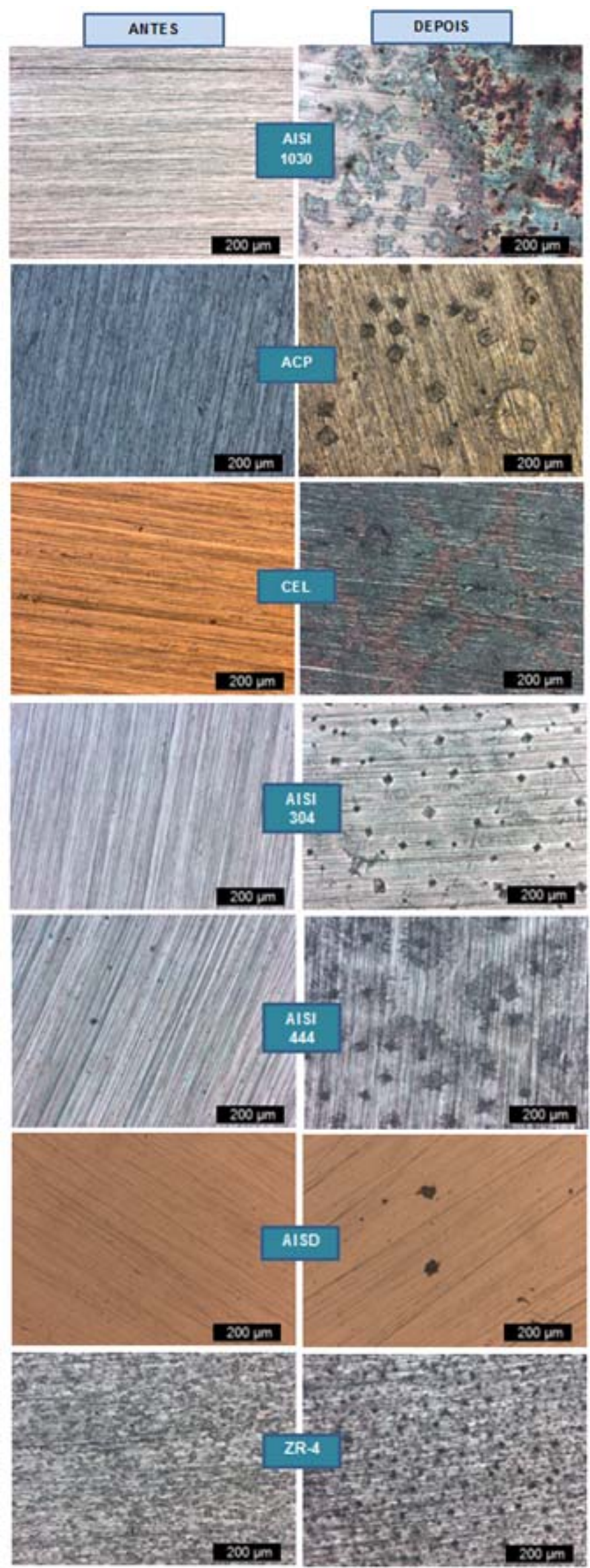

Figura 6 - Micrografias antes e após o ensaio de polarização. Microscópio Ótico (100X). Fonte: Própria do autor. 
Os ensaios de polarização potenciodinâmica cíclica realizados permitem a visualização do comportamento das ligas ferrosas e não ferrosas frente aos efeitos da corrosão causada pelo ataque dos íons cloretos presentes na solução.

Algumas ligas apresentaram maior suscetibilidade à corrosão por pites, essas foram: o alumínio comercialmente puro (ACP), os aços inoxidáveis austenítico (AISI 304) e ferrítico (AISI 444) e o zircaloy-4 (ZR-4). Isso foi constatado devido aos parâmetros de resistência à corrosão obtidos e ao formato das curvas de polarização. A ocorrência da corrosão na forma de pites ficou evidente no exame comparativo das micrografias antes e depois do ensaio para cada uma dessas ligas.

As ligas que apresentaram menor suscetibilidade à corrosão por pites foram: o aço carbono (AISI 1030), o cobre eletrolítico (CEL) e o aço inoxidável super duplex (AISD). Sendo que o aço carbono AISI 1030 e o CEL apresentaram corrosão do tipo generalizada de forma intensa, concordando com as curvas obtidas e com as análises comparativas das micrografias.

O Aço inoxidável super duplex ASTM A 890 / A 890M (AISD) apresentou pites em pequena quantidade na sua superfície, e apresentou os melhores parâmetros nas curvas de polarização em comparação com todas as demais ligas, indicando que esse material apresenta as melhores propriedades de resistência à corrosão por pites dentre as ligas comparadas no presente estudo.

\section{REFERÊNCIAS}

1 GENTIL V. Corrosão. 5.ed. Rio de Janeiro: LTC - Livros Técnicos e Científicos Editora S.A, 2007.

2 JAMBO HCM, FÓFANO S. Corrosão - Fundamentos, Monitoração e Controle. Rio de Janeiro: Editora Ciência Moderna, 2008.

3 ROBERGE PR. Handbook of Corrosion Engineering. New York: McGraw-Hill, 1999.

4 BABOIAN R, DEAN JR SW, HACK HP, HIBNER EL, SCULLY JR. Corrosion tests and standards: application and interpretation. 2. ed. Baltimore: ASTM International, 2005 [acesso em: 21 abr. 2015]. Disponível em: https://goo.gl/WClaTw.

5 CARDOSO JL. Avaliação e comparação da resistência à corrosão por pites do aço super austenítico AL 6XN PLUS TM e dos aços inoxidáveis austeníticos da série AISI 304L, 316L e 317L. 2011. 77 f. Dissertação (Mestrado) - Programa de Pós-graduação em Engenharia e Ciência de Materiais, Departamento de Engenharia Metalúrgica e de Materiais, Universidade Federal do Ceará, Fortaleza, 2011 [acesso em 20 abr. 2015]. Cap. 4. Disponível em: http://goo.gl/AAapOK.

6 BITONDO C, BOSSIO A, MONETTA T, CURIONI M, BELUCCI F. The effect of annealing on the corrosion behaviour of 444 stainless steel for drinking water applications. Corrosion Science, 2014 [acesso em 15 mar. 2016], v. 87, p.6-10. Disponível em: http://goo.gl/aslhnE.

7 MARTINS M, CASTELETTI LC. Caracterização microestrutural e comportamento à corrosão do aço inox super duplex ASTM A890 GR 6A. In: CONGRESSO ANUAL DA ABM, 59., 2004, São Paulo. Publicação. São Paulo: Associação Brasileira de Metalurgia, Materiais e Mineração, 2004. p. 1 - 18.

8 MARTINS AS. Estudo comparativo da resistência à corrosão dos aços inoxidáveis super duplex ASTM A890 / A890M Grau 5A e 6A. 2014. 73 f. Dissertação (Mestrado) Programa de Pós-graduação em Engenharia e Ciência de Materiais, Departamento de Engenharia Metalúrgica e de Materiais, Universidade Federal do Ceará, Fortaleza, 2014 [acesso em 14 mai. 2015]. Cap. 5. Disponível em: http://goo.gl/WVi2Zb. 